\title{
Molecular Arrangements in Two-Dimensional $J$-Aggregate Monolayers of Cyanine Dyes
}

\author{
Valery V. Prokhorov, ${ }^{@}$ Sergey I. Pozin, Dmitry A. Lypenko, Olga M. Perelygina, \\ Eugene I. Mal'tsev, and Anatoly V. Vannikov
}

Dedicated to Academician Aslan Tsivadze on the occasion of his $70^{\text {th }}$ Anniversary

A. N. Frumkin Institute of Physical Chemistry and Electrochemistry, Russian Academy of Sciences, 119991 Moscow, Russia,

${ }^{\circledR}$ Corresponding author E-mail: vprokh@gmail.com

\begin{abstract}
Atomic force microscopy was used for the study of two-dimensional J-aggregates monolayer structures of two cyanine dyes with a high-resolution. Two coexisting morphologically different types (i.e. the bilayer rectangular stripes and monolayer curve shaped leaves) were observed for 3,3'-di( $\gamma$-sulfopropyl)-4,4',5,5'-dibenzo-9-ethylthiacarbocyanine betaine pyridinium (dye D-1). The morphological diversity, the crystallographic peculiarities and the monolayer height $\sim 1.35 \mathrm{~nm}$ are selfconsistently explained by the difference in the molecular packing arrangements, i.e. the ladder for stripes and the staircase for leaves. A building unit of both J-aggregate types is a symmetric monolayer with the same height and slip angle $\sim 15^{\circ}$, composed of all-trans monomers with anti-parallel up-down orientation. For the two-dimensional sheets of the second cyanine dye (5,5'-dichloro-3,3'-disulfopropyl thiacyanine sodium salt) Dye-2 the fine substructure formed by close packed parallel narrow threads was resolved. The stripes were inclined at the angle $\sim 30^{\circ}$ to the J-aggregates long side providing for the first time the direct microscopic support for the probable staircase molecular arrangement. It is speculated that the quazi-one-dimensional staircase-type and ladder-type units are building blocks of the two-dimensional aggregates of various cyanine dyes.
\end{abstract}

Keywords: J-Aggregates, cyanine dyes, self-assembly, monolayers, molecular arrangement, atomic force microscopy.

\section{Молекулярное строение Авумерных монослоев $J$-агрегатов цианиновых красителей}

\author{
В. В. Прохоров, ${ }^{@}$ С. И. Позин, А. А. Аыпенко, О. М. Перелыгина, Е. И. Мальцев,
} А. В. Ванников

Посвящается акаgемику Аслану Юсуповичу Циваgзе по случаю его 70-летнего юбилея

Институт физической химии и электрохимии им. А.Н. Фрумкина РАН, 119991 Москва, Россия

${ }^{\circledR}$ E-mail: vprokh@gmail.com

\begin{abstract}
Атомно силовая микроскопия использовалась для визуализации с высоким разрешением двумерных монослоев J-агрегатов двух цианиновых красителей. Два морфологически различных типа (бислойнье прямоугольные полосы имонослойные листовые структуры в формелистьев) наблюдались для первого красителя (пиридиниевая соль 3,3'-ди(ү-сульфопропил)-4,4',5,5'-дибензо-9-этилтиокарбоцианин бетаина, D-1). Морфологический полиморфизм, кристаллографические особенности и толщина монослоя 1.35 нм были объяснены в рамках самосогласованной модели, предполагающей молекулярную упаковку типа прямой (ladder) и косой (staircase) лестниц соответственно для полос и листьев. Строительной единицей обоих типов J-агрегатов является симметричный монослой из all-trans мономеров с анти-параллельной в направлении нормали к плоскости слоя ориентаџией, образующих стэкинг и сдвинутых латерально на угол $\sim 15^{\circ}$. В двумерных монослойных
\end{abstract}


J-агрегатах второго красителя (5,5'-дихлоро-3,3'-дисульфопропилтиацианинат натрия, D-2) обнаружена тонкая линейчатая подструктура, образованная параллельными плотно упакованными узкими линиями. Линии наклонены под углом $30^{\circ}$ к прямой стороне агрегатов, и их наблюдение является первым микроскопическим подтверждением упаковки типа косой лестниць J-агрегатов. В завершении приводятся аргументы, что квазиодномерные прямые и косые лестничные структуры являются строительными блоками двумерных агрегатов различных ичианиновых красителей.

Ключевые слова: J-Агрегаты, цианиновые красители, самосборка, монослои, молекулярное строение, атомно силовая микроскопия.

\section{Introduction}

Cyanine dyes like some other types of organic molecules with conjugated $\pi$-system easily self-assemble into supramolecular aggregates with unusual optical properties, i.e. with a narrow intense absorption band shifted bathrochromically (in $J$-aggregates) or hypsochromically (in $H$-aggregates) with respect to that of monomers. ${ }^{[1-2]}$ The absorption band frequency shift has long ago been explained in terms of molecular exciton theory, i.e. via the formation of delocalized Frenkel-type exciton states in stacked adjacent coherently coupled chromophores. ${ }^{[1-3]}$ Due to the unique optoelectronic properties, $J$ - and $H$-aggregates of cyanine dyes have been used long ago as light sensitizers in silver halides color photography ${ }^{[4]}$ and widely studied recently as components for nonlinear optical and photorefractive devices, ${ }^{[5]}$ cavity QED structures, ${ }^{[6]}$ single-mode optical waveguides, ${ }^{[7]}$ lightemitting dopants to electron-hole conducting polymer layers in polymer OLEDs, ${ }^{[8]}$ light-sensitizing agents in complexes with quantum-dots ${ }^{[9]}$ and for biosensing applications. ${ }^{[10]}$ At the nanometer scale, the lateral slippage of transitional dipoles of adjacent $\pi$-stacked molecules takes place in $J$-aggregates and a small slip angle $\alpha$ is formed (Figure 1a). A large molecular slippage (small angle $\alpha<54.7^{\circ}$ ) results in a red shift (in $J$-aggregates), while a small slippage brings about a blue shift (in $H$-aggregates). ${ }^{[1-3]}$

At a mesoscale, the $J$-aggregates manifest a complex morphological and structural variability, so that various structures have been observed at different dyes concentrations and solution conditions. For thiacyanine, ${ }^{[1-13,17]}$ pseudoisocyanine ${ }^{[14]}$ and some carbocyanine dyes ${ }^{[15-17,19]}$ the optical microscopy, ${ }^{[1,12,18]}$ transmission electron microscopy (TEM) ${ }^{[13-16]}$ and atomic force microscopy (AFM) measurements ${ }^{[11,12,17-19]}$ revealed several morphological groups of $J$-aggregates such as extended two-dimensional rods, strings and sheets ${ }^{[11,12,15,17,19]}$ and giant tubes, ${ }^{[12,16]}$ fibrils, ${ }^{[14]}$ quasi one-dimensional stripes, twisted ribbons and tubules. ${ }^{[15-}$ ${ }^{17]}$ Precise AFM measurements of the height of $J$-aggregates extended monolayers and fibrillar structures provide important estimations structural information defining the vertical dimension of a $J$-aggregate elementary cell and imposing limitations on probable $J$-aggregate structural models. ${ }^{[17,19]}$

Three basic models of molecular packing arrangements in $J$-aggregates with the laterally slipped adjacent dye molecules were supposed, i.e. the staircase, ladder and brickwork models ${ }^{[1-3]}$ represented schematically in Figure 1. The requirement of small slip angles is valid for all $J$-aggregates molecular models irrespective of $J$-aggregate morphology observed at a mesoscale. Geometrically the most simple morphology is a two-dimensional flat or curved monolayer (or bilayer) formed by stacked dye molecules with molecular planes oriented normally to the monolayer plane. However even in this simplest case, there are still no convincing experimental evidences in favor of any particular model of the molecular arrangement in $J$-aggregates despite the numerous long term discussions in literature. ${ }^{[11-13,15,17]}$ The reason is that the microscopic visualization of $J$-aggregates monolayers with a molecular resolution, which could give direct information on the molecular arrangement, has not been provided whilst indirect data obtained by other techniques is not unambiguious. The molecular orientation in $J$ - and $H$-aggregates can be determined from the anisotropy of optical properties at polarized optical measurements, ${ }^{[2,11,12]}$ however the polarized optical microscopy data provide no direct information on the molecular arrangement of adjacent stacked dye molecules. Important information on the angular parameters of the elementary cell can be supplied by TEM or AFM nanoscale measurements of crystallographic habits of $J$-aggregate two-dimensional structures, i.e. the symmetry and angles of polygonal shapes. Yet these measurements have not been performed up to now for $J$-aggregates. In our recent work, ${ }^{[19]}$ we have used the high resolution AFM imaging of crystallographic peculiarities of two dimensional $J$-aggregate monolayers of carbocyanine dye 3,3'-di(g-sulfopropyl)4,4',5,5'-dibenzo-9-ethylthiacarbocyanine betaine pyridinium salt (referred below as D-1) combined with the subangstrom a)

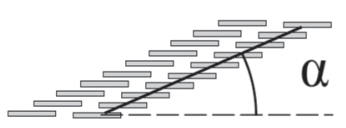

b)

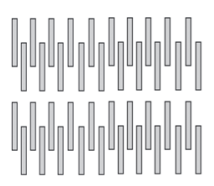

c)

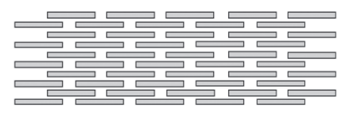

Figure 1. The staircase (a), ladder (b) and brickwork (c) molecular arrangements of dye molecules in $J$-aggregates; $\alpha$ - slip angle. Molecular planes are normal to the figure plane. 
accuracy of monolayer height estimations. It turned out, that these two sets of AFM data complement each other and provide the self-consistent explanation of the observed morphological diversity via the difference in two suggested molecular packing arrangements, i.e. the staircase and ladder types. Moreover, the ladder and staircase molecular arrangements were shown to coexist in the dye solution.

\section{Experimental}

\section{Samples Preparation}

The chemical structure of the carbocyanine dyes used (refereed below as D-1 and D-2) and probable structures of their antiparallel dimers are shown in Figure 2a and b. For the deposition on mica the dyes were dissolved in deionized water with conductivity $17 \mathrm{MOhm}^{-1} \mathrm{~cm}^{-1}$. For AFM imaging, the molecular aggregates were deposited upon a freshly cleaved mica surface at a room temperature for a time $3 \mathrm{~min}$ from water solutions with a concentration of $\sim 0.5 \mathrm{mg} / \mathrm{ml}$. After that, the solution excess was blown off by an air stream.

\section{AFM Imaging}

AFM measurements were conducted at ambient air on SmartSPM (AIST-NT, Zelenograd, Russia). Standard commercial silicon cantilevers were used for routine measurements and ultrasharp probes (carbon whiskers grown at the tip of standard
AFM probes) with a probe curvature radius of several nanometers were used for high-resolution measurements. The probe spring constant was within $\sim 10-40 \mathrm{~N} / \mathrm{m}$, and the resonance frequency was within 200-350 kHz. The routine off-line AFM image analysis was performed by Femtoscan software (http://spm.genebee.msu.ru/ products/fmspog.html).

Particular attention was paid to the choice of the optimal AFM operational regime. For standard AFM probes, the attraction non-contact regime of probe-surface interactions with small amplitudes of probe oscillations (typically $\sim 10-20 \mathrm{~nm}$ ) was used in accordance with general recommendations. ${ }^{[20]}$ For ultrasharp probes the scanning was conducted both in the attraction and in the repulsuion regimes of probe-surface interactions and the highest resolution was achieved in the repulsion regime (see Figure 3c). The resolution increase in the repulsion regime is caused by better surface profiling due to the direct probe/surface repulsive contact at conditions of significantly reduced probe/surface interaction forces. ${ }^{[17,21]}$ The details of the AFM methodology are given elsewhere. ${ }^{[17]}$

\section{Results and Discussion}

\section{The Dye D-1 J-Aggregates with the Stripe and Leaf Morphologies and their Structural Models}

Figure 3a shows the AFM topography image of two coexisting types of two-dimensional sheets of D-1 molecular aggregates: (1) the extended stripes with straight parallel a)

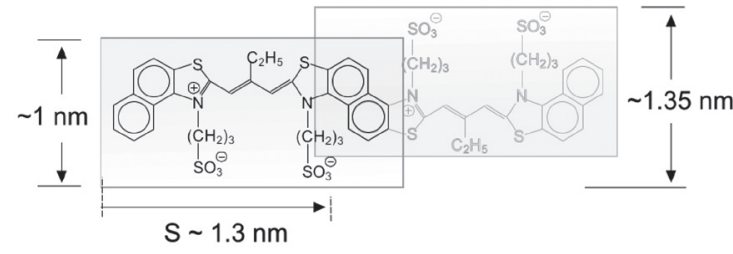

b)

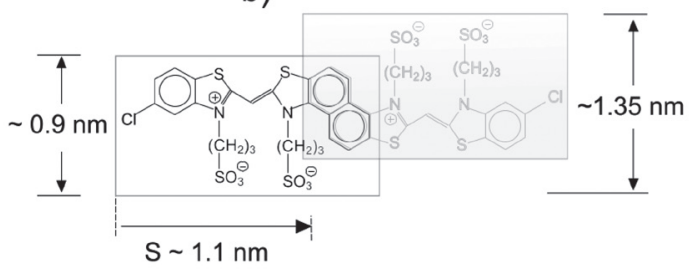

Figure 2. Probable structures of anti-parallel dimers of dyes D1 (a) and D2 (b) and their dimensions. In the represented dimers front view the second molecules are selected by grey.
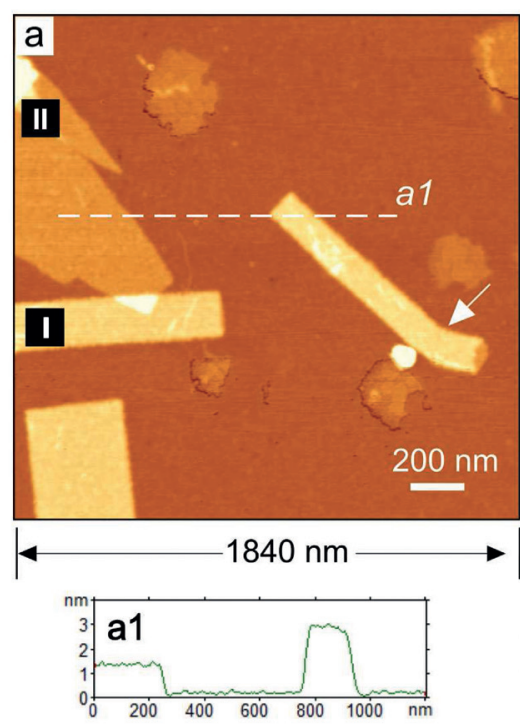

b)
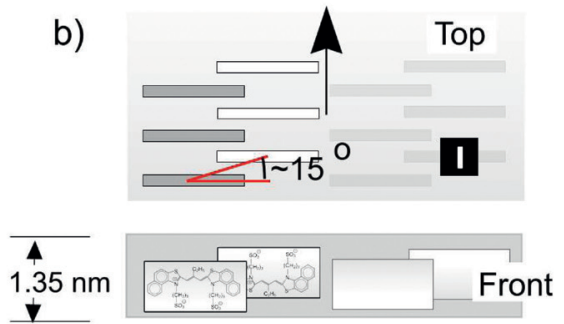

c)
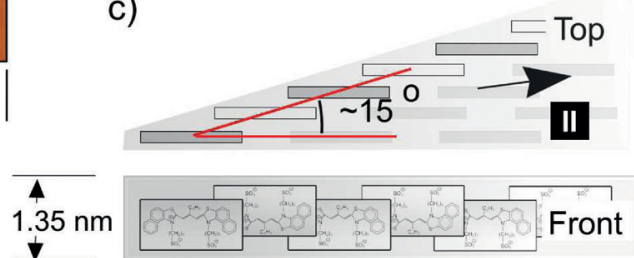

Figure 3. (a) The AFM height image of $J$-aggregates of the dye D-1 with the bilayer stripe (I) and the monolayer leaf (II) morphology, (a1) The height profile along the dashed lines al in (a). (b,c) The structural models of stripes (b) and leaves (c). Black arrows show the long direction of $J$-aggregates. 
long sides (I), (2) the leaves with curved shapes and small acute angles at the vortexes (frequently $\sim 15-17^{\circ}$ ) (II). The ends of stripes were found to be different, i.e. the ragged, rectangular and blunt chisel in a shape. Some leaves and stripes have overlaps and/or folds indicating the formation in the solution bulk and subsequent overlapping/folding upon adsorption to mica. The analysis of fine peculiarities in the area of overlapping or folding indicates the high lability of leaves and stripes and their probable reorganization on the surface after overlapping/folding. ${ }^{[17,19]}$ As it can be deduced from the height profile in Figure 3a1, the leaves have a monolayer height $(\sim 1.3-1.35 \mathrm{~nm})$ whilst the stripes are bilayers $(\mathrm{H} \sim 2.6-2.8 \mathrm{~nm})$, although the monolayer stripes have also been found. ${ }^{[19]}$ The monolayer height of some stripes and other stripes peculiarities (for example the inflexion point shown by the white arrow in Figure 3 a) indicate that stripes can't be giant tubes ${ }^{[13]}$ originally formed in a solution and subsequently squashed at adsorption to mica by surface forces, as it was argued in ref. ${ }^{[12]}$ for the morphologically similar stripes of TC dye. The structural models of stripes and leaves are represented in Figure 3b,c which explain in a self-consistent way: 1) the observed monolayer height 1.3-1.4 $\mathrm{nm}, 2$ ) the typical crystallographic habits (the acute angle $\sim 15^{\circ}$ for leaves and rectangular shapes of stripes) and 3 ) some fine peculiarities such as blunt chisel shapes of some stripes. ${ }^{[19]}$ In Figure 3a,b, both models imply a symmetric monolayer comprised of monomers in all-trans conformation. The long axes of dye molecules are oriented parallel to each other and to mica plain whereas the molecular planes are oriented normally to mica. The anti-parallel molecular orientation in the up-down direction with the aliphatic chains bilaterally disposed on each side of a monolayer follows form the observed monolayer height $\sim 1.35 \mathrm{~nm}$ (whilst the upper limit for the vertical molecular dimension is $\sim 1.0 \mathrm{~nm}$ as shown in Figure 2a). The requirement of the maximum overlap of the stacked $\pi$-electron chromophores for the antiparallel up-down molecular orientation is fulfilled at the nonzero lateral displacement (slippage) $\mathrm{S} \sim 1.3 \mathrm{~nm}$ of two adjacent stacked molecules (Figure 2a). This displacement generates the slip angle $\alpha=\operatorname{atan}(\mathrm{D} / \mathrm{S}) \sim 15-17^{\circ}$ which is observed in the vortexes of leaves (Figure 3a), where D is the plane-to-plane intermolecular distance which is typically considered to be $\sim 0.35-0.4 \mathrm{~nm} \cdot{ }^{[22,23]}$ Noteworthy to say, that for this particular dye the unique anti-parallel up-down arrangement of adjacent molecules slipped by $\mathrm{S} \sim 1.3 \mathrm{~nm}$ comes from the essentially not-in-line arrangement of three joint cycles of $\pi$-electron chromophores (Figure 2a). The observed rectangular ends of stripes could be explained by two alternative conceivable models with the ladder (Figure 1b) and brickwork arrangements (Figure 1c) having different molecular orientation with respect to the aggregates long axis, i.e. across and along the long axis of stripes. Importantly, some observed crystallographic habits (i.e. the blunt chisel in a shape ends of some stripes) make the laddertype arrangement more preferable. ${ }^{[19]}$

\section{The Dye D-2 J-Aggregates with the Threadlike Substructure}

Figure 4 shows the AFM topography images of $J$-aggregates of dye D-2. The large scale image in Figure 4a shows the two-dimensional monolayer sheets with imperfect polygonal shapes. Some extended aggregates have parallel long sides similar to the D-1 stripes however the rectangular shapes are not observed for this dye. Figure $4 \mathrm{~b}$ shows the extended $J$-aggregate with one long side being relatively straight and other side being curved. Figure $4 \mathrm{c}$ shows the high resolution image of the central area of this aggregate. Surprisingly, the top surface of the $J$-aggregate monolayer which seems smooth on large scale images has a fine substructure. This substructure is formed by close packed parallel narrow threads of a variable width inclined at the angle $30^{\circ}$ to the aggregate straight long side. Very probable interpretation of this substructure is shown schematically in Figure $4 c$ by the superposed row of white laterally slipped segments. This row represents the staircase arrangement with the slip angle of $\sim 30^{\circ}$ and molecular long axes parallel to the straight long side of the $J$-aggregate. The observed threads width is typically small being in the range of 7-15 $\mathrm{nm}$ (see the height profile in Figure 4c1), still it is several
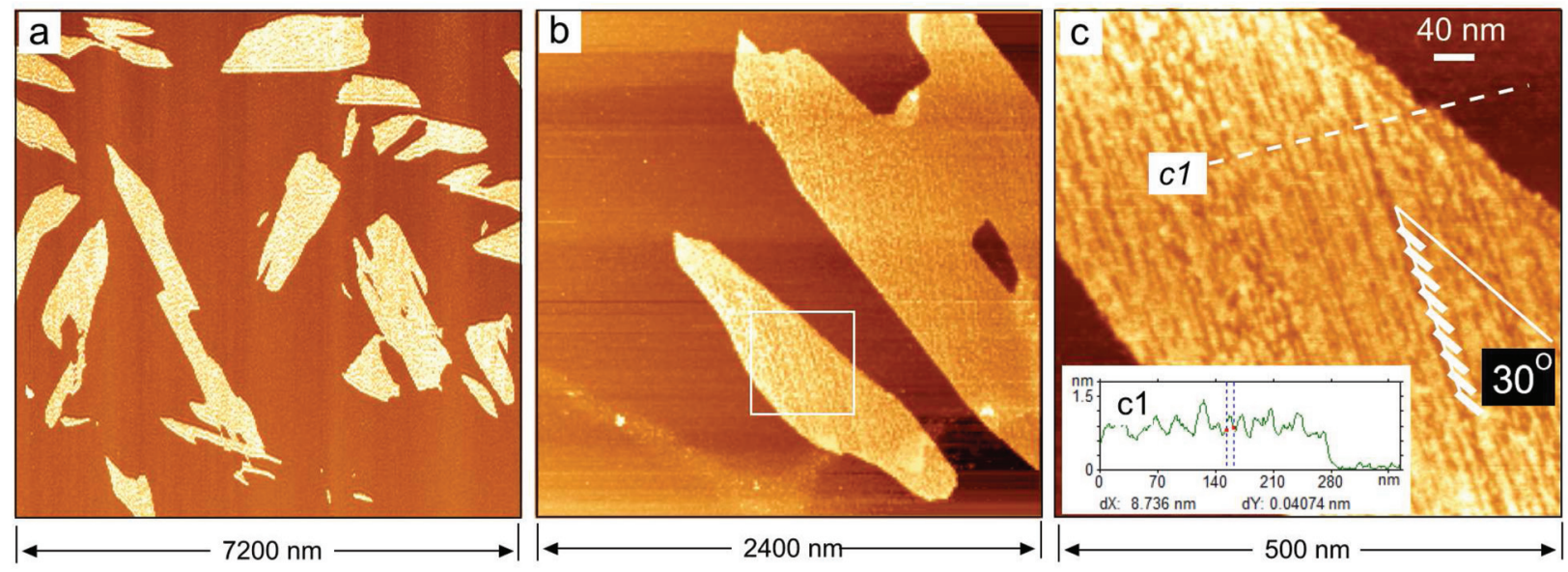

Figure 4. The AFM height images of $J$-aggregates of dye D-2 on mica deposited from a water solution with $\mathrm{c}=3 \mathrm{mg} / \mathrm{ml} 4 \mathrm{~h}$ after the dye dissolution. (a,b) The large scale images. (c) The small scale image of the area selected by the square in (b). (c1) The height profile along the dashed line $c l$ in (c). The row of white segments in (c) shows schematically the staircase arrangement of dye D-2 molecules in narrow t. 
times larger than the width of a single isolated staircase which is expected to be about $\sim 1 \mathrm{~nm}$. We thus suggest that the threads are lateral aggregates of several "elementary" staircases. As a resume, the AFM resolve for the first time the fine substructure of the $J$-aggregate monolayer. Actually, for this dye the monolayer is built from quazi-one-dimensional threads consisting of several staircases. The height profile in Figure 4c1 indicates the height variation up to $\sim 1.4 \mathrm{~nm}$. Similar to the above consideration for the D-1 dye, the D-2 dye monolayer height of $\sim 1.4 \mathrm{~nm}$ can be explained by the arrangement of adjacent dye molecules in an antiparallel way in the up-down direction such as shown in the dimer model in Figure 2b. In the model in Figure 2b, the lateral slippage $\mathrm{S}$ of adjacent molecules is $\sim 0.95 \mathrm{~nm}$. This value is however notably smaller than $\mathrm{S} \sim 0.61 \mathrm{~nm}$ implied by the staircase model with the slip angle $\sim 30^{\circ}\left(\mathrm{S}=\mathrm{D} / \tan \left(30^{\circ}\right)\right.$, where $\mathrm{D} \sim 0.35$ $\mathrm{nm}$ is the intermolecular spacing). This discrepancy indicates that the real molecular arrangement in dye D2 staircases is different from that of suggested in the model in Figure $2 b$. Interestingly, the observed in Figure 4c slip angle is close to $\sim 27^{\circ}$ expected for the dyes with smaller chromophores. ${ }^{[23]}$

\section{Some General Remarks on the Staircase, Ladder and Brickwork Molecular Arrangements in J-Aggregates}

The irregular threadlike substructure of twodimensional sheets of dye J2 in Figure 4 resembles the fine parallel banded substructure observed on electron microscopy images in ref. ${ }^{[24]}$ for 3,3'-bis( $\beta$-carboxyethy 1$)$ 5,5'-dichloro-9-methylthiacarbocyanine. Contrary to the dye D-2 forming extended $J$-aggregates with irregular polygonal shapes the cyanine dye in ref. ${ }^{[24]}$ forms $\mathrm{H}$-aggregates with morphology of extended stripes with parallel long sides. The stripes have narrow subbands with a repeat distance integer multiples of $2.8 \mathrm{~nm}$; the long molecular axes in subbands are perpendicular to the bands axis.

The packing of various rod-like molecules normally to the preferable growth direction is a typical case at a crystallization both in a solution and on the surface. ${ }^{[21]}$ Thus, the growth of one-dimensional ladders both inclined (in staircases) or normal (in $J$ - and $H$-ladders) is expected on a base of rather general consideration. For flat molecules such as cyanine dyes the strong $\pi-\pi$ stacking interaction of adjacent heterocycles (assumed in the models in Figures $3 \mathrm{~b}$ and c) is expected to result in a faster growth in the direction normal to molecular planes generating the ladder or staircase arrangements. In a particular case of cyanine dyes, the formation of energetically preferable one-dimensional ladderlike oligomers was demonstrated by the computer modeling of the aggregation of theamonomethinecyanine dye in water. ${ }^{[25]}$ The important conclusion, convincingly derived from the present AFM results for the D-1 dye is that both packing arrangements (i.e. the staircase and the ladder) can be realized in different $J$-aggregates grown in the same solution.

The second point which is worth to note is that the slip angle in $J$-aggregates of different cyanine and carbocyanine dyes is expected to be small (within $\sim 15-30^{\circ}$ ) irrespectively on a particular chemical structure. Consequently, the orientation of dye molecules with respect to the long dimension of macroscopic $J$-aggregates turns out to be different in $J$-aggregates with the staircase and the ladder molecular arrangements. In a particular case of D-1 dye this statement is exemplified in Figures $3 b$ and $3 c$ where the molecules are oriented normally to and approximately along the $J$-aggregate long axis (shown by black arrow). Experimentally, the polirazation optical microscopy frequently reveals the two $J$-aggregate types with mostly longitudinal and transversal molecular orientations. ${ }^{[12]}$ Thus, the polarization microscopy data can be generally explained by invoking the staircase (with approximately the longitudinal molecular orientation as in Figure 3c) and the ladder (with the transversal molecular orientation as in Figure 3b) molecular arrangements.

Up to date there are several publications in which the staircase, brickwork and herringbone molecular arrangements of some dyes in two-dimensional monolayers formed on different substrates have been directly resolved microscopically by using STM and SFM techniques. ${ }^{[26-29]}$ The monolayers growth and their molecular structures were however essentially promoted by the surface forces influencing the surface assembly at the molecular level. Thus the direct comparison of the molecular arrangements observed in refs. ${ }^{[26-29]}$ with those of in solution grown $J$ - and $H$-aggregates such as considered in the present work seems to be irrelevant.

Historically, the brickwork longitudinal molecular arrangement combining both the $J$-type coupling and tight two-dimensional molecular packing was suggested as alternative to the ladder-like arrangement for the explanation of optical linear dichroism data for pseudoisocyanine chloride (PIC) $J$-aggregates oriented in flow. ${ }^{[3]}$ However it was later shown by electron microscopy that the PIC underlying structure is fibrillar at a nanoscale, not a monolayer. ${ }^{[14]}$ One can see from the above consideration, that the introduction of the brickwork arrangement is not necessary both for the explanation of the polarization microscopy data and from a general crystallographic viewpoint. Neverthelees, we suggest that the brickwork model can't be excluded from a consideration in a general case. The brickwork and the ladder basic structural difference is that the ladder (as well as the staircase) is the quazi-one-dimensional structure, whilst the monolayer with the brickwork arrangement is actually the two-dimensional crystal. Experimanatlly, at large solution oversaturation the rapid growth proceeds via the formation of highly anizometric extended structures whilst at small oversaturation the slower growth is observed with the formation of essentially two-dimensional polygonal crystal shapes. It is expected from this viewpoint that the one-dimensional ladders and the staircases (or their lateral aggregates) form quickly in concentrated dye solutions whilst the two-dimensional brickwork arrangement can also be grown at smaller concentrations for a longer growth time.

\section{Conclusions}

The main results of the present study can be summarized as follows. First, it is demonstrated that the morphological diversity of $J$-aggregates can be explained by the difference in the molecular packing arrangements, i.e. the ladder and the staircase. Thus the structurally different packing arrangements should be generally considered to be physically coexisting at same solution conditions rather than alternative as it is frequently assumed. Second, for the two- 
dimensional $J$-aggrgegate monolayers the high resolution AFM reveals the narrow stripe substructure inclined to the long $J$-aggregate sides. The inclination angle $\sim 30^{\circ}$ is close to the slip angle expected for $J$-aggregates providing for the first time the microscopic support for the staircase molecular arrangement. It is speculated that the building units of two-dimensional $J$-aggregate monolayers are quazi-onedimensional units composed of several molecular rows with the staiscase or ladder molecular arrangement.

Acknowledgments. We are indebted to Prof. Boris I. Shapiro for kindly providing us with cyanine dyes. The work was supported by the Russian Federation Ministry of Education and Science.

\section{References}

1. Kuhn H., Kuhn C. Chromophore Coupling Effects. In: J-Aggregates (Kobayashi T., Ed.). Singapore: World Scientific, 1996. p. 1-40.

2. Wurthner F., Kaiser T.E., Saha-Muller C.R. Angew. Chem. Int. Ed. 2011, 50, 3376-3410.

3. Czikkely V., Forsterling H.D., Kuhn H. Chem. Phys. Lett. 1970, 6, 207-210.

4. Tani T., Seki K., Yoshihara K., Hanna J. Int. J. Photoenergy 2006, 2006, 1-8.

5. Wurthner F., Wortmann R., Meerholz K. Chem. Phys. Chem. 2002, 3, 17-31.

6. Tischler J.R., Bradley M.S., Bulovic V., Song J.H., Nurmikko A. Phys. Rev. Lett. 2005, 95, 036401.

7. Takazawa K., Kotahama Y., Kimura Y., Kido G. Nano Lett. 2005, 5, 1293-1296.

8. Mal'tsev E.I., Lypenko D.A., Shapiro B.I., Brusentseva M.A., Milburn G.H.W., Wright J., Hendriksen A., Berendyaev V.I., Kotov B.V., Vannikov A.V. Appl. Phys. Lett. 1999, 75, 18961898.

9. Walker B.J., Bulovic V., Bawendi M. G. Nano Lett. 2010, 10, 3995-3999.

10. Achyuthan K.E., Bergstedt T.S., Chen L., Jones R.M., Kumaraswamy S., Kushon S.A., Ley K.D., Lu L., McBranchD.,
Mukundan H., Rininsland F., Shi X., Xia W., Whitten D.G. Biotechnol. Prog. 2008, 24, 964-971.

11. Yao H., Kitamura S., Kimura K. Phys. Chem. Chem. Phys. 2001, 3, 4560-4565.

12. Yao H. Annu. Rep. Prog. Chem., Sect. C: Phys. Chem. 2004, 100, 99-148.

13. von Berlepsch H., Brandenburg E., Koksch B., Bottcher C. Langmuir 2010, 26, 11452-11460.

14. von Berlepsch H., Bottcher C., Dahne L. J. Phys. Chem. B 2000, 104, 8792-8799.

15. von Berlepsch H., Bottcher C., Ouart A., Burger C., Dahne S., Kirstein S. J. Phys. Chem. B 2000, 104, 5255-5262.

16. von Berlepsch H., Kirstein S., Hania R., Pugzlys A., Bottcher C. J. Phys. Chem. B 2007, 111, 1701-1711.

17. Prokhorov V.V., Mal'tsev E.I., Perelygina O.M., Lypenko D.A., Pozin S.I., Vannikov A.V. Nanotechnology in Russia 2011, 6, 286-297.

18. Vranken N., Foubert P., Kohn F., Gronheid R., Scheblykin I., Van der Auweraer M., De Schryver F.C. Langmuir 2002, 18, 8407-8417.

19. Prokhorov V.V., Pozin S.I., Lypenko D.A., Perelygina O.M., Mal'tsev E.I., Vannikov A.V. Chem. Phys. Lett. 2012, 535, 9499.

20. Garcia R., Perez R. Surf. Sci. Rep. 2002, 47, 197-301.

21. Prokhorov V.V., Klinov D.V., Chinarev A.A., Tuzikov A.B., Gorokhova I.V., Bovin N.V. Langmuir 2011, 27, 5879-5890.

22. Bakalis L.D., Rubtsov I., Knoester J. J. Chem. Phys. 2002, 117, 5393-5403.

23. van der Auweraer M., Scheblykin I.G. Chem. Phys. 2002, 275, 285-306

24. Emerson E.S., Conlin M.A., Rosenoff A.E., Norland K.S., Rodriguez H., Chin D., Bird G.R. J. Phys. Chem. 1967, 71, 2396-2401.

25. Chuev G.N., Fedorov M.V. J. Chem. Phys. 2009, 131, 074503.

26. Kawasaki M., Ishii H. Chem. Lett. 1994, 23, 1079-1082.

27. Wolthaus L., Schaper A., Möbius D. Chem. Phys. Lett. 1994, 225, 322-326.

28. Owens R.W., Smith D.A. Langmuir 2000, 16, 562-567.

29. Janssens G., Touhari F., Gerritsen J.W., van Kempen H., Callant P., Deroover G., Vandenbroucke D. Chem. Phys. Lett. 2001, 344, 1-6. 